\title{
Does ultrasonic elastography show high sensitivity in diagnosing benign and malignant thyroid nodules?
}

\author{
Jiangfeng Wu^, Yunlai Wang, Yun Jin \\ Department of Ultrasound, The Affiliated Dongyang Hospital of Wenzhou Medical University, Dongyang, China \\ Correspondence to: Jiangfeng Wu. Department of Ultrasound, The Affiliated Dongyang Hospital of Wenzhou Medical University, No. 60 Wuning \\ West Road, Dongyang 322100, China. Email: wjfhospital@163.com. \\ Response to: Zhou Y, Chen H, Qiang J, et al. Systematic review and meta-analysis of ultrasonic elastography in the diagnosis of benign and malignant \\ thyroid nodules. Gland Surg 2021;10:2734-44.
}

Submitted Nov 19, 2021. Accepted for publication Dec 24, 2021.

doi: $10.21037 /$ gs-21-773

View this article at: https://dx.doi.org/10.21037/gs-21-773

We read with interest the recent article written by Zhou and colleagues entitled "Systematic review and meta-analysis of ultrasonic elastography (USE) in the diagnosis of benign and malignant thyroid nodules" (1). Zhou et al. highlight that USE has high value in the diagnosis of benign and malignant thyroid nodules. We thank the authors for such valuable evidence and would like to make several comments on this study.

First, in the abstract section of the article, the results of this study showed that the pooled sensitivity and specificity were $72.26 \%$ and $95.35 \%$, and the area under the receiver operating characteristic curve (AUC) was 0.857, showing that USE has slightly high false-negative rate (27.74\%). The missed diagnosis of thyroid cancer may result in metastasis of cervical lymph nodules or distant organs and lead to a threat to patient's health. Then, we do not agree with authors about USE showing high sensitivity in the diagnosis of thyroid cancer and believe that USE could not be used for exclusion of malignant thyroid nodules completely.

Second, in the conclusions section, the authors expressed the view that USE could reduce the false negative cases. However, the present meta-analysis aimed to assess the value of USE diagnosing thyroid cancer, and did not compare the diagnostic performance between USE and other diagnostic methods such as routine ultrasound directly. Therefore, we consider that USE reducing the false negative cases could not be confirmed on the basis of this study.

Third, in the last paragraph of the article, Zhou et al. Revealed that USE is an alternative diagnostic modality for patient who is not suitable for or rejects biopsy diagnosis. However, there is no quantitative comparison of the diagnostic performance between USE and biopsy in the main text. Fine needle biopsy is still the most effective and used method evaluating thyroid nodules (2). Then, we think that this conclusion is also not reliable.

Finally, the data in Table 2 were not consistent with the included studies. In Wang et al.' study (3), 86 patients with 102 thyroid nodules were included, which were not consistent with 52 patients with 72 thyroid nodules in the Table 2. Furthermore, in Table 2, the number of sums of the true positive cases, false positive cases, false negative cases, and true negative cases is not consistent with the total number of cases in each study. In the inclusion and exclusion criteria section, articles which were randomized controlled trials (RCTs) were enrolled in this meta-analysis, however, the study design of Wang et al. is a diagnostic study. We believe that the data in this study should be further revised and verified for accuracy.

We make these comments only to promote the clinical utility of USE and recommend that the authors of similar such studies may take into account these additional points.

$\wedge$ ORCID: 0000-0002-5036-799X. 


\section{Acknowledgments}

Funding: None.

\section{Footnote}

Provenance and Peer Review: This article was a standard submission to the journal. The article did not undergo external peer review.

Conflicts of Interest: All authors have completed the ICMJE uniform disclosure form (available at https://gs.amegroups. com/article/view/10.21037/gs-21-773/coif). The authors have no conflicts of interest to declare.

Ethical Statement: The authors are accountable for all aspects of the work in ensuring that questions related to the accuracy or integrity of any part of the work are appropriately investigated and resolved.

Open Access Statement: This is an Open Access article

Cite this article as: $\mathrm{Wu} \mathrm{J}$, Wang $\mathrm{Y}$, Jin Y. Does ultrasonic elastography show high sensitivity in diagnosing benign and malignant thyroid nodules? Gland Surg 2022;11(1):305-306. doi: 10.21037/gs-21-773 distributed in accordance with the Creative Commons Attribution-NonCommercial-NoDerivs 4.0 International License (CC BY-NC-ND 4.0), which permits the noncommercial replication and distribution of the article with the strict proviso that no changes or edits are made and the original work is properly cited (including links to both the formal publication through the relevant DOI and the license). See: https://creativecommons.org/licenses/by-nc-nd/4.0/.

\section{References}

1. Zhou Y, Chen H, Qiang J, et al. Systematic review and meta-analysis of ultrasonic elastography in the diagnosis of benign and malignant thyroid nodules. Gland Surg 2021;10:2734-44.

2. Oo ZP, Hlaing AM, Kyi KCS, et al. An overview of thyroid fine-needle aspiration practice in Myanmar. Gland Surg 2020;9:1747-53.

3. Wang J, Wei W, Guo R. Ultrasonic elastography and conventional ultrasound in the diagnosis of thyroid micronodules. Pak J Med Sci 2019;35:1526-31. 